\title{
Letramento digital no livro didático de inglês Prime 3: uma análise crítica
}

\author{
Raquel Rodrigues \\ UFRJ
}

\begin{abstract}
Resumo
Este estudo busca avaliar em que medida verifica-se uma adequação das atividades didático-pedagógicas da unidade 2 - Digital Learners - à proposta teórico-metodológica assumida pelos autores no livro didático de inglês Prime 3 para o ensino médio com relação à promoção de letramento digital. A avaliação é feita a partir de uma visão sociointeracional de língua e aprendizagem, devido à coerência com orientações de documentos oficiais vigentes (BRASIL, 2014/2006) e da literatura (VYGOSTSKY, 1978 [1998]; de KALANTZIS e COPE 2000/2012; MARCUSCHI, 2008: ROJO e MOURA, 2012, entre outros autores). Utilizo a gramática sistêmicofuncional (HALLIDAY, 2014) como instrumento teórico-metodológico. $\mathrm{Na}$ análise, o discurso do livro do professor explora a ideia de estimular oportunizações de experimentação com a língua em colaboração para motivar a apropriação de gêneros digitais podendo transformar conhecimento co-construído para uso no mundo real. No entanto, as atividades contribuem para um conhecimento técnico, abstrato e normativo das linguagens digitais.
\end{abstract}

Palavras Chave: material didático, ensino de inglês, letramento digital

\begin{abstract}
This study seeks to evaluate to what extent the pedagogic activities in Unit 2 - Digital Learners - is adequate for the theoretical-methodological approach the authors claim to adopt with regard to the promotion of digital literacy. The evaluation is conducted from a sociointeractive perspective of language and learning due to its coherence with the current guidelines in official documents (BRASIL 2010,2014) and the literature (VYGOSTSKY, 1978 [1998]; de KALANTZIS e COPE 2000/2012; MARCUSCHI, 2008: ROJO e MOURA, 2012, among other authors). Systemic-functional grammar (HALLIDAY, 2014) is used as a theoretical-methodological tool. The analysis shows that the book exploits the idea of encouraging opportunities for experimenting with language in collaboration in order to motivate the appropriation of digital genres, making it possible to transform coconstructed knowledge for use in the real world. However, the activities contribute to a technical, abstract and normative knowledge of digital languages.
\end{abstract}

Keywords: learning materials, ELT, digital literacy

\section{CONTEXTUALIZAÇÃO}

Atualmente existe no Brasil um crescente interesse do mercado editorial na área de desenvolvimento de materiais didáticos de ensino de inglês para a rede pública de 
ensino devido ao Programa Nacional do Livro Didático (PNLD) como sistema de avaliação adotado pelo Ministério da Educação (MEC). O PNLD não incluía Língua Estrangeira até 2011; neste ano de 2014 presenciamos a quarta vez que livros do componente são avaliados e somente a segunda vez para o Ensino Médio.

Dessa forma, para viabilizar a distribuição de suas coleções, após aquisição destas pelo MEC, editoras de materiais didáticos de ensino de língua inglesa precisam submeter seus livros ao Programa atendendo a diversos critérios sobre visão de ensinoaprendizagem, linguagem, práticas sociodiscursivas, e práticas pedagógicas. Dentro deste contexto, as editoras têm empreendido esforços em assimilar os critérios de avaliação do programa e incorporá-los em seus materiais ao longo dos últimos anos.

Após alguns anos elaborando conteúdo para materiais didáticos digitais $\mathrm{e}$ multimídia para uso em diversos contextos educacionais, e recentes experiências escrevendo conteúdo para unidades de livro didático impresso, assim como, avaliando materiais no programa de pós-graduação, meu interesse se intensificou com relação aos materiais produzidos para as escolas publicas e pelo PNLD.

A obra que serviu de corpus para esta pesquisa é o livro Prime 3, recentemente aprovada no edital de 2015 sob um novo título, e ligeira adaptação. De acordo com o Guia PNLD 2015 de ensino médio (BRASIL, 2014), "foram observadas a coerência e a adequação da abordagem teórico-metodológica assumida pela coleção, no que diz respeito à proposta didático-pedagógica explicitada e aos objetivos visados.” Da mesma forma, o documento afirma que para a análise do Manual do Professor, foi verificada a adequação da obra à linha pedagógica nela apresentada.

Para uma análise da abordagem teórico-metodológica assumida no Manual do Professor com relação a letramento digital foi utilizada a gramática sistêmico funcional (HALLIDAY, 2014), em duas categorias: o sistema de transitividade e o de modo. A escolha do quadro teórico metodológico de Halliday para uma analise crítica do discurso é comum e frutífera entre pesquisadores tanto em materiais didáticos quanto em outros meios de produção, circulação e consumo de textos e discursos não necessariamente limitados à esfera educacional. Isto se dá pelo fato da teoria sistêmico funcional auxiliar as pesquisas interpretativas e análises que envolvem ideologias através de uma averiguação sistemática do materialismo linguístico, promovendo evidências para fundamentar interpretações de forma concreta.

Para analisar as atividades didático-pedagógicas, assim como a coerência entre estas e o que o Manual do Professor afirma, utilizo categorias da pedagogia de 
(multi)letramentos de Kalantzis e Cope (2000, 2012), da perspectiva sociointeracional de linguagem, aprendizagem e desenvolvimento devido ao "papel dominante da experiência social no desenvolvimento humano" (VYGOTSKY, 1978 [1998], p. 26), além de teorias sobre de materiais didáticos encontradas na literatura em Harwood (2010); Pereira \& Gottheim, (2012) e Tomlinson, (2011).

A análise do material busca entendimento sobre as seguintes questões:

- O que propõe a abordagem teórico-metodológica assumida pela coleção conforme explicitada no Manual do Professor com relação a letramento digital?

- Qual a linha didático-pedagógica das atividades propostas na unidade 2 - sobre letramento digital?

- Em que medida verifica-se uma adequação das atividades didático-pedagógicas da unidade 2 - sobre letramento digital - à proposta teórico-metodológica assumida pela coleção?

De acordo com o Guia PNLD 2015 (BRASIL, 2014), “o livro didático de língua estrangeira assume um papel relevante quando produzido conforme fundamentos teórico-metodológicos que garantam o engajamento discursivo dos estudantes e favoreçam o compromisso de uma formação escolar construtora da cidadania".

Espera-se que as análises e considerações aqui apresentadas possam contribuir para a elaboração e distribuição de materiais didáticos de língua inglesa cada vez mais engajados com o empoderamento e inserção dos alunos em práticas sociodiscursivas diversas e autênticas, inclusive no e através do meio digital. O letramento digital é um componente propício para tal, porém pouco explicitado nos critérios do PNLD e bastante polêmico ainda quanto a sua concepção e oportunização.

Neste artigo abordo algumas questões primordiais para o ensino de linguagens, códigos e suas tecnologias no ensino médio de acordo com os documentos oficiais (BRASIL 2006) e critérios contemplados no PNLD (BRASIL 2014). O primeiro aspecto da fundamentação teórica que sustenta os documentos oficiais é a importância da interação para a inserção social, na qual faço menção aos pressupostos da teoria sociointeracional e da pedagogia crítica de (multi)letramentos. Em seguida foco no letramento digital especificamente, na questão da autenticidade e participação ativa, e por fim da importância do material didático propor tarefas além de exercícios. 
Após o debate teórico, explicito como utilizo a gramática sistêmico-funcional de Halliday (2014) para gerar os dados e analisar criticamente o discurso do Manual com base em seu materialismo linguístico. A seguir analiso criticamente as atividades da unidade 2 no Livro do Aluno a partir de todos os pressupostos que fundamentam o trabalho, isto é, com relação à interação para inserção social que elas propiciam ou não, se estão em coerência com o discurso sociointeracional do Manual, se proporcionam participação ativa e autêntica através de tarefas, e afinal se há uma adequação entre o discurso do Manual e as atividades didáticas da unidade.

\section{O ENSINO DE LINGUAGENS, CÓdigos E SUAS TECNOLOGIAS PARA O ENSINO MÉDIO NO BRASIL}

Os documentos oficiais (BRASIL 2006, 2014) que orientam as práticas pedagógicas nacionais no ensino médio são baseados em pesquisas e estudos contemporâneos que levam em consideração o desenvolvimento das psicologias da aprendizagem e de teorias linguísticas específicas próprias para o momento sociohistórico atual. São levados em conta, como fator primordial neste contexto, os letramentos necessários para inserção social das novas gerações. O objetivo da educação e da aprendizagem não é apenas o acesso ao mercado de trabalho, mas a diferentes áreas de conhecimento visando um maior entendimento sobre o mundo em que vivemos e empoderamento para uma maior atuação no mundo através de práticas sociodiscursivas.

Podemos destacar nas Orientações Curriculares para o Ensino Médio (BRASIL, 2006) o seguinte trecho sobre critérios para a proposta pedagógica de ensino de língua e letramentos na seção Linguagens, códigos e suas tecnologias:

Para orientar o trabalho de elaboração da proposta pedagógica, uma compreensão teórica sobre a linguagem é necessária, (...) entender a linguagem como um modo de ação social por meio da qual as pessoas estão agindo no mundo. (...)

Essas dimensões da natureza construcionista, socio-interacional e situada da linguagem são importantes, por que trazem à tona o fato de que a linguagem não ocorre em um vácuo social (...). Essa compreensão é extremamente importante no mundo altamente semiotizado da globalização, uma vez que possibilita situar os discursos a que somos expostos e recuperar sua situacionalidade social.

(...) Esse tipo de conhecimento tem sido apontado como extremamente importante para dar conta de letramentos multisemióticos que têm transformado o letramento tradicional (da letra) em um tipo de letramento insuficiente para dar conta daqueles necessários para agir na vida contemporânea. Além disso, tem sido enfatizado o modo híbrido ou multimodal como esses meios multisemióticos estão combinados e organizados em textos e hipertextos. Tais letramentos estão intimamente 
relacionados, portanto, com os requisitos do mundo do trabalho e da cidadania. (BRASIL, 2006, p. 36-38)

\section{A IMPORTÂNCIA DA INTERAÇÃO PARA INSERÇÃO SOCIAL}

A abordagem sociointeracional, assim como uma pedagogia crítica de (multi)letramentos, aponta para a possibilidade de expansão das áreas de participação dos alunos em práticas sociais diversas através da linguagem. Portanto, a pedagogia crítica com uma perspectiva de aprendizagem e de linguagem sociointeracional se destaca como a mais apropriada para o ensino de língua inglesa na contemporaneidade.

A teoria de aprendizagem sociointeracional constitui uma perspectiva de ensino como prática sociocultural que oportuniza situações de interação com o outro e com o meio devido ao "papel dominante da experiência social no desenvolvimento humano" (VYGOSTSKY, 1978 [1998], p. 26). Segundo MARCUSCHI (2008, p. 19), a língua é vista como "um conjunto de práticas enunciativas e não como forma descarnada", ao afirmar que "a enunciação humana é sempre um ato social", em consonância com a visão de Bakhtin e Voloshinov (1929 [2006]) sobre a natureza social da língua.

De acordo com tal teoria, para uma aprendizagem efetiva e crítica, é primordial promover oportunidades do aluno se engajar sociodiscursivamente no processo, coconstruindo entendimentos na interação social.

Os signos só emergem, decididamente, do processo de interação entre uma consciência individual e uma outra. E a própria consciência individual está repleta de signos. A consciência só se torna consciência quando se impregna de conteúdo ideológico (semiótico) e, conseqüentemente, somente no processo de interação social. (BAKHTIN e VOLOSHINOV (1929 [2006], p.32)

O material didático, de acordo com os documentos oficiais e as teorias que os embasam, deve buscar promover uma pedagogia crítica e de (multi)letramentos, termo cunhado pelo New London Group, que tem por maior inspiração os múltiplos canais de comunicação, ou seja, diferentes mídias e semioses. Ainda dentro da ideia de multiplicidade, o conceito abraça também a diversidade cultural e linguística, afinal a comunicação nos dias de hoje, de acordo com Cope e Kalantzis (2000), deixou de ser primariamente linguística para ser multimodal Atualmente os autores optaram pelo termo letramentos (KALANTZIS \& COPE, 2012), porém com o mesmo conceito de multiplicidade. 
Kalantzis e Cope (2012) defendem uma pedagogia de letramentos críticos para o atual momento sociohistoricocultural por ser uma abordagem que reconhece que letramentos são plurais; que valoriza os alunos como criadores de significado, como agentes, como participantes e como cidadãos ativos, além de usar o aprendizado de letramentos como uma ferramenta que habilite os alunos a tomar controle sobre as maneiras que significados são construídos em suas vidas.

\section{O LETRAMENTO DIGITAL}

A teoria de (multi)letramentos destaca, além do aspecto crítico intrínseco à sua pedagogia, as possibilidades oferecidas pelas novas mídias digitais. Kalantzis e Cope (2012) sugerem apresentar aos alunos o que as mais novas mídias permitem criar em projetos que empoderem os alunos a acessar recursos culturais e de conhecimento e cruzar a barreira digital. Os autores afirmam que as novas mídias aumentam as oportunidades pedagógicas criando um espaço contemporâneo onde as vozes dos alunos podem ser expressas de forma autêntica através de vídeos, podcast, blogs, etc.

No Brasil, Coscarelli e Ribeiro (2005, p. 9) concebem letramento digital como "a ampliação do leque de possibilidades de contato com a escrita também em ambiente digital (tanto pra ler quanto para escrever)" e também mencionam os novos gêneros discursivos originados na mídia digital, como o email e a conversa de chat. Afinal todo texto se organiza em gêneros do discurso, isto é, "tipos relativamente estáveis de enunciados" (BAKHTIN, 1979 [2003], p. 262) Outra característica dos gêneros é a riqueza e a variedade destes.

A riqueza e a variedade dos gêneros do discurso são infinitas, pois a variedade virtual da atividade humana é inesgotável, e cada esfera dessa atividade comporta um repertório de gêneros do discurso que vai diferenciando-se e ampliando-se à medida que a própria esfera se desenvolve e fica mais complexa. (BAKTHIN, 1953 [2003], p. 279)

Essa característica faz com que possamos contemplar, na análise e na elaboração de materiais didáticos, novos gêneros que surgiram com o advento da internet, por exemplo. A apropriação crítica e transformadora de tais gêneros constitui o aspecto mais importante entre as possibilidades de inclusão social dos sujeitos que o computador e a internet oferecem (COSCARELLI; RIBEIRO, 2005). 


\section{A QUESTÃO DA AUTENTICIDADE E PARTICIPAÇÃO ATIVA}

Numa pedagogia sociointeracional crítica de (multi)letramentos, o material deve apresentar textos (não apenas escritos) autênticos, tal como concebidos por Widdowson (1979), isto é, semelhantes a textos em circulação fora da sala de aula, porém não necessariamente genuínos. Da mesma forma, as atividades também devem ser autênticas focando na participação ativa para uma educação transformadora, diferente da antiga pedagogia passiva de treinamento.

Harwood (2010, pp. 6-7) destaca a importância de conectar o conteúdo dos textos e atividades no material didático significativamente com o contexto e a própria vida social dos alunos. Ele destaca a autonomia sócio-cultural, isto é, saber atuar no mundo usando a língua, acima da autonomia individual e uma mudança de foco do papel do aluno como 'recipiente' para 'colaborador'. Tomlinson (TOMLINSON, 2010, p.83) lista dentre vários princípios para a elaboração de materiais didáticos, promover oportunidades de usar a língua para alcançar objetivos comunicativos e estimular o envolvimento dos alunos (tanto intelectual quanto emocional e estético). Outra característica que ele considera essencial em materiais didáticos é replicar atividades da vida real (TOMLINSON, 2010, p.94).

\section{A IMPORTÂNCIA DE PROPOR TAREFAS}

Tomilinson (2010, pp. 88-93) também afirma a necessidade dos alunos terem experiências com a língua (preferencialmente em colaboração) permitindo que eles façam descobertas sobre o uso por conta própria com o auxilio do material e do professor, ao invés de serem passivos de informações explicitas quanto ao uso da língua. Por fim, ele sugere replicar atividades da vida real para facilitar a transferência da aprendizagem para fora da sala de aula. Da mesma forma, Ellis (2010, p.35) contrasta os conceitos de atividades propostas que ele denomina como tarefas e atividades de gramática contextualizadas. De acordo com sua definição, atividades são "exercícios" (mesmo quando situados/contextualizados) nos quais os alunos não escolhem seus recursos linguísticos e é pouco provável que haja qualquer negociação de significado, por exemplo, não tendo nenhuma lacuna na informação ou opinião envolvida, ou seja, não há produção comunicativa resultante da atividade proposta. 
Atividades pedagógicas podem ser consideradas tarefas, segundo Ellis, se atenderem a quatro critérios:

1) Ter foco primário no significado;

2) Os alunos escolhem os recursos linguísticos e não linguísticos necessários para completar a tarefa;

3) A tarefa deve levar a processos de uso da língua no mundo real;

4) Uma performance bem sucedida da tarefa é determinada por examinar se os alunos alcançaram o resultado comunicativo pretendido. (ELLIS, 2010, p 35)

Utilizo neste artigo o termo atividade sem a conotação marxista da teoria da atividade, para me referir a atividades pedagógicas englobando tanto exercícios quanto tarefas. Duas razões pelas quais tarefas são tão essenciais. A base teórica é que:

1) os alunos vão obter sucesso em desenvolver controle completo de seu conhecimento linguístico se eles experimentarem usa-lo em condições de operação reais; e 2) o verdadeiro desenvolvimento de interlíngua (isto é, o processo de aquisição de novo conhecimento linguístico e reestruturação do conhecimento existente) só pode ocorrer quando a aquisição se dá incidentalmente, como produto do esforço em se comunicar (ELLIS, 2010, pp. 38-39).

Ellis explica que a ideia não é deixar de ensinar gramática, mas fazer com que os alunos percebam a estrutura gramatical ao desenhar tarefas que destaquem a estrutura gramatical de forma que seja essencial depreender seu significado e o torne necessário para a comunicação. Ele concede que atividades de gramática tradicionais que pedem um aprendizado intencional são possivelmente mais efetivas em promover aquisição, porém podem resultar apenas em conhecimento explícito ao invés do conhecimento implícito necessário para usar a língua com facilidade e naturalmente na comunicação.

\section{METODOLOGIA}

Como toda pesquisa qualitativa de base interpretativista, este estudo pretende construir entendimentos sobre uma situação específica. A preocupação desta pesquisa documental é de cunho social e enfoca a questão da importância e falhas na implementação de letramento digital dentro de uma pedagogia crítica de (multi)letramentos no material didático para o ensino médio na escola pública no Brasil. 
O corpus desta pesquisa conta com o volume 3 da coleção PRIME para o ensino médio, que contou com a melhor avaliação do PNLD 2012. Os elementos analisados são as oportunidades providas para um letramento digital amparado pela pedagogia crítica e da perspectiva de ensino sociointeracional.

Para a geração de dados, inicialmente foi necessária a obtenção do documento em questão, o livro PRIME 3 e a transcrição do trecho do Manual do Professor que descreve o letramento digital no Livro do Aluno. A partir daí o trecho foi separado em orações para uma análise sistêmico-funcional. Em seguida, fez-se necessário criar uma tabela para categorizar os tipos de atividades da Unidade 2 de acordo com o que os enunciados propunham.

Para responder às perguntas de pesquisa, os dados foram gerados a partir dos sistemas de transitividade e modo, da abordagem sistêmico-funcional de Halliday (2014), em uma análise da proposta teórico-metodológica assumida pela coleção Prime no volume 3, conforme explicitada no Manual do Professor, com relação a letramento digital. Através do sistema de transitividade procuro entender como o Manual se representa em sua proposta, e da perspectiva do sistema de modo, como se propõe na interação com o leitor-aluno. Esse primeiro momento foca nos processos verbais das orações no trecho do Manual do Professor que se dedica a descrever como o letramento digital é trabalhado no Livro do Aluno.

A teoria sistêmico-funcional de Halliday é bastante apropriada para analisar discursos através do materialismo linguístico em um texto qualquer e chegar a uma interpretação ideológica bem fundamentada através das análises das escolhas sistêmicas do autor. As escolhas linguísticas podem revelar e mesmo omitir muitas questões ideológicas importantes. Como o próprio Halliday (2014, p 54) pontua, “a análise lexicogramatical de um texto é uma ferramenta importante a ser usada para abordar problemas em uma comunidade em diferentes esferas, como a educação, saúde, administração e comércio." Halliday também aponta para as novas possibilidades de compartilhamento público de textos multisemióticos promovidas por avanços tecnológicos. Ele afirma que

tecnologias móveis e da web vem mudando as possibilidades de 'compartilhamento' de formas dramáticas com toda uma nova gama de opções como mensagens de email, mensagens de texto, blogs, tweets e outros formatos associados às mídias sociais e que como resultado a distinção entre a esfera privada de 'compartilhamento' de valores e opiniões e a esfera pública de explora-los tem se tornado difusa. (HALLIDAY, 2014, p. 42) 
Em um segundo momento, a análise da linha didático-pedagógica das atividades propostas na unidade 2 do Livro do Aluno, e sua coerência com relação a sua representação no Manual do Professor, foi realizada com base na teoria de (multi)letramentos, com foco no letramento digital. Utilizo também o arcabouço teórico oferecido pelas contribuições na área de elaboração e avaliação de materiais didáticos com base na noção de tarefas autênticas de Ellis (2010), dos princípios de colaboração e participação ativa, propostos por Harwood (2010) e Tomlinson (2010), assim como os fundamentos da visão sociointeracional de ensino como prática sociocultural que oportuniza situações de interação com o outro e com o meio.

\section{A ANÁLISE DOS DADOS}

\section{O Manual do Professor}

Utilizando o sistema de transitividade de Halliday (2014), podemos inferir do trecho dedicado ao letramento digital algumas noções expressas pelo materialismo linguístico das orações quanto à representação de tal letramento nas atividades como concebida pelos autores e, através sistema de modo (HALLIDAY, 2014), podemos analisar a proposta com relação à forma de interação entre o material e o leitor. Abaixo se encontra transcrito o trecho referente a letramento digital no Manual do Professor do livro Prime 3:

Letramento digital refere-se à habilidade de localizar, entender, avaliar e produzir conhecimento usando tecnologia digital. Nossos alunos do Ensino Médio podem ser classificados como digital speakers da era digital por saberem lidar habilmente com os recursos dessa era. No volume 3, exploramos a presença do mundo virtual na sociedade contemporânea pelo uso de vários gêneros digitais, pelo incentivo à utilização das ferramentas colaborativas da Internet, como blogs e wikis, além das sugestões de sites relacionados aos temas das unidades na seção Going beyond. Ao fazerem uso dos sites recomendados, os alunos podem ampliar sua visão de mundo, assim como refletir sobre assuntos da atualidade relacionados ao mundo teen e ao que têm de lidar no processo de amadurecimento em direção à vida adulta.

Ao longo do livro, principalmente na seção Going beyond, sites com conteúdos similares ao tema da unidade são recomendados para que os alunos possam ter ampliadas as suas oportunidades de interações reais em contextos autênticos de comunicação.

Incentivamos também o uso da tecnologia como ferramenta de trabalho pelo uso de programas básicos como os editores de texto (Microsoft Word), os de apresentação (Microsoft PowerPoint), e os de planilha (Microsoft Excel) para facilitar e respaldar o trabalho de edição e apresentação de textos. Os programas de verificação ortográfica, os de gramática e os dicionários online são outros recursos da tecnologia recomendados para a mesma finalidade. Acreditamos que tais recursos podem fortalecer as experiências de aprendizagem, ampliando e estendendo o tempo e o espaço das atividades face a face em sala de aula. (DIAS; JUCÁ; FARIA, 2010, p. 8) 
Pensando no texto como representação, para responder quais processos são mais recorrentes no trecho segue uma breve análise dos grupos verbais nas orações.

\section{Processos dos grupos verbais no sistema de transitividade}

1. Letramento digital refere-se à habilidade de localizar, entender, avaliar e produzir conhecimento usando tecnologia digital.

\section{Processo relacional atributivo}

2. Nossos alunos do Ensino Médio podem ser classificados como digital speakers da era digital por saberem lidar habilmente com os recursos dessa era.

Processo relacional identificador (passivo)

3. No volume 3, exploramos a presença do mundo virtual na sociedade contemporânea pelo uso de vários gêneros digitais, pelo incentivo à utilização das ferramentas colaborativas da Internet, como blogs e wikis, além das sugestões de sites relacionados aos temas das unidades na seção Going beyond.

\section{Processo material abstrato operativo transformativo}

(Tipo de resultado: aprimoramento)

4. Ao fazerem uso dos sites recomendados, os alunos podem ampliar sua visão de mundo,

\section{Processo material abstrato operativo transformativo}

(Tipo de resultado: aprimoramento)

assim como refletir sobre assuntos da atualidade relacionados ao mundo teen e ao que têm de lidar no processo de amadurecimento em direção à vida adulta.

\section{Processo mental cognitivo}

5. Ao longo do livro, principalmente na seção Going beyond, sites com conteúdos similares ao tema da unidade são recomendados

\section{Processo verbal}

para que os alunos possam ter ampliadas as suas oportunidades de interações reais em contextos autênticos de comunicação.

\section{Processo material abstrato receptivo transformativo}

(Tipo de resultado: aprimoramento) 
6. Incentivamos também o uso da tecnologia como ferramenta de trabalho pelo uso de programas básicos como os editores de texto (Microsoft Word), os de apresentação (Microsoft PowerPoint), e os de planilha (Microsoft Excel) para facilitar e respaldar o trabalho de edição e apresentação de textos.

\section{Processo material abstrato operativo transformativo}

(Tipo de resultado: aprimoramento)

7. Os programas de verificação ortográfica, os de gramática e os dicionários online são outros recursos da tecnologia recomendados para a mesma finalidade.

\section{Processo material abstrato receptivo transformativo}

(Tipo de resultado: aprimoramento)

8. Acreditamos que tais recursos podem fortalecer as experiências de aprendizagem, ampliando e estendendo o tempo e o espaço das atividades face a face em sala de aula.

Processo mental cognitivo

Processo material abstrato operativo transformativo

(Tipo de resultado: aprimoramento)

Trecho do Manual dedicado ao letramento digital dividido em orações com destaque para os processos pelo sistema de transitividade.

Analisando as orações que compõem o texto no Manual do Professor referente ao trabalho desenvolvido para a promoção de letramento digital, os dados emergentes revelam que metade delas apresenta processos materiais abstratos operativos transformativos com resultado de aprimoramento. O trecho sobre letramento didático aponta, portanto, para uma representação de práticas didáticas como meio de transformação e aprimoramento de uso da tecnologia.

No excerto 3, por exemplo, os autores afirmam: "No volume 3, exploramos a presença do mundo virtual na sociedade contemporânea", qualificando a prática como processo material abstrato operativo transformativo com resultado de aprimoramento, e as circunstâncias são explicitadas da seguinte forma: "pelo uso de vários gêneros digitais, pelo incentivo à utilização das ferramentas colaborativas da Internet, como blogs e wikis, além das sugestões de sites relacionados aos temas das unidades na seção Going beyond." Isto sugere que o uso de gêneros digitais e incentivo à utilização de ferramentas colaborativas da Internet possibilitam processos transformativos de 
aprimoramento. Portanto, é preciso investigar como se dá tal incentivo no Livro do Aluno.

Apesar de o manual afirmar, por exemplo, no excerto 5 que os alunos (beneficiário) possam ter ampliadas (processo material transformativo) as suas oportunidades de comunicação (meta), não fica claro quem é o ator dos processos, pois o "agente da passiva" é omitido, talvez por uma razão estratégica. Porém podemos pressupor, com base no contexto, que esse ator são as práticas didáticas, especialmente se considerarmos que essa é uma oração intercalada à anterior que afirma que "[a]o fazerem uso dos sites recomendados, os alunos podem ampliar sua visão de mundo, assim como refletir sobre assuntos da atualidade relacionados ao mundo teen e ao que têm de lidar no processo de amadurecimento em direção à vida adulta".

A função de tais transformações e aprimoramentos seria, conforme o texto, oportunizar maior interação real em contextos autênticos de comunicação sobre assuntos atuais e relevantes e desta forma expandir as experiências de aprendizagem em atividades face-a-face em sala de aula.

Olhando para o texto com foco na interação, foi utilizado o sistema de modo (HALLIDAY, 2014) para uma análise dos grupos verbais.

Sistema de modo
Nossos alunos do Ensino Médio podem ser classificados como digital speakers da era digital
por saberem lidar habilmente com os recursos dessa era.
Ao fazerem uso dos sites recomendados, os alunos podem ampliar sua visão de mundo, assim
como refletir sobre assuntos da atualidade relacionados ao mundo teen e ao que têm de lidar no
processo de amadurecimento em direção à vida adulta.
Ao longo do livro, principalmente na seção Going beyond, sites com conteúdos similares ao
tema da unidade são recomendados para que os alunos possam ter ampliadas as suas
oportunidades de interações reais em contextos autênticos de comunicação.
Acreditamos que tais recursos podem fortalecer as experiências de aprendizagem, ampliando e
estendendo o tempo e o espaço das atividades face a face em sala de aula.
Trecho do Manual dedicado ao letramento digital dividido em orações contendo modalização. 
O sistema de modo nos permite observar - por outro prisma - que como forma de interação e troca entre o texto no Manual do Professor e o leitor, a relação estabelecida é altamente modalizada, pois o manual afirma (utilizando o indicativo declarativo) determinadas sentenças sobre a coleção ao leitor (que, como alvo, é geralmente o professor ou neste estudo, o pesquisador). Portanto, os autores se comprometem relativamente pouco com relação aos objetivos alçados.

Os autores não afirmam que a meta é realizada, mas realizável, como se pode notar nos excertos destacados nesta seção pelo uso do verbo auxiliar poder indicando possibilidade. Dessa forma, as transformações e aprimoramentos pretendidos são modalizados de forma que configuram uma intenção, inclinação e possibilidade, afinal metade das orações apresentam modulações de inclinação. Tais inclinações são vistas como possibilitadas através de estímulo, recomendações e incentivo à utilização de certas ferramentas para ampliar oportunidades de interações reais em contextos autênticos de comunicação, além de facilitar e respaldar o trabalho de edição e apresentação de textos e expandir as atividades de interação oral em sala de aula.

\section{As atividades do livro didático (Unidade 2 - Digital learners)}

\begin{tabular}{|l|l|}
\hline Escolher a(s) alternativa(s) corretas (múltipla escolha) & 9 \\
\hline Relacionar (match) & 7 \\
\hline Completar a frase (resposta fechada) & 1 \\
\hline Completar a frase (resposta pessoal) & 1 \\
\hline Compartilhar informação oralmente & 1 \\
\hline Debater & 2 \\
\hline Numerar os itens (resposta pessoal) & 1 \\
\hline Pergunta direta sobre um texto (resposta fechada) & 3 \\
\hline Pergunta direta sobre um texto (pessoal) & 1 \\
\hline Escolher uma alternativa (resposta pessoal) & 4 \\
\hline Categorização semântica ou gramatical & 2 \\
\hline Exercício gramatical estrutural (acrescentar -ing) & 1 \\
\hline Escrever um texto & 1 \\
\hline Palavras-cruzadas & 1 \\
\hline Tarefa & 1 \\
\hline
\end{tabular}


A unidade sobre letramento digital se inicia com uma página rica em elementos visuais/imagéticos icônicos do mundo digital. O Manual do Professor sugere "explorar a página, conversando com os alunos sobre o título da unidade $\mathrm{e}$ as imagens apresentadas" (DIAS; JUCÁ; FARIA, 2010: 11). Esta é uma proposta interessante por estimular o conhecimento prévio dos alunos ao propor uma discussão a cerca daqueles elementos tão intrínsecos a um letramento digital e os significados criados e compartilhados sobre eles.

As atividades seguintes pedem que os alunos exemplifiquem um projeto escolar no qual tenham utilizado alguma ferramenta tecnológica (em uma atividade em que devem completar frases com o nome da disciplina, o nome da ferramenta e do projeto), e em seguida compartilhem oralmente as informações com os colegas.

As atividades que se seguem são conceituais, na medida em que os alunos devem assinalar a opção correta ou relacionar um termo a seu conceito. Em apenas quatro atividades eles devem dar respostas pessoais: em uma ranqueando condições necessárias para a aprendizagem ao longo da vida, conforme a proposta pedagógica; em outras duas eles devem assinalar com que frequência realizam atividades de aprendizagem em meio digital e pensando sobre seus hábitos; e por fim em uma outra atividade devem apenas assinalar qual tipo de aprendiz digital acreditam ser.

$\mathrm{Na}$ vasta maioria das atividades propostas, os alunos não precisam criar, comunicar ou colaborar. Esses três verbos são apresentados em um texto da unidade como os três Cs da era digital, porém os aprendizes só precisam ligar cada uma dessas palavras a seu conceito. Os alunos são posicionados como passivos de informações explícitas quanto ao uso dos recursos digitais citados como ferramentas "exploradas" no texto sobre letramento digital do Manual do Professor.

Uma atividade pede que assinalem quais ferramentas digitais podem ser usadas para trabalhar em colaboração com colegas online e para discutir as respostas. Há um ícone para o professor ir ao Manual, onde há uma sugestão de que "se achar que é o caso, combinar para os alunos fazerem um blog da turma ou um trabalho de produção de texto em um espaço wiki”. A sugestão é altamente pertinente, relevante e oportuna, porém não há uma proposta específica, uma tarefa. Sobre o que irão escrever? Como será realizado? Não há diretrizes, porém já é mais do que estávamos acostumados a ter em materiais didáticos no passado. É notável o progresso.

Em seguida, uma atividade em que os alunos devem completar frases com uma das duas opções dadas explica como funciona uma wiki. As atividades de leitura 
incluem perguntas sobre quem escreveu o artigo online exibido na página e onde foi publicado, chamando atenção para a fonte de produção e distribuição do texto no mundo real ou simulado, mas não de letramento crítico, pois os alunos não são levados a refletir sobre relações de poder ou discursos hegemônicos. Tais atividades ainda são, portanto contextualizadas, porém não são tarefas autênticas, pois não se assemelham a - nem simulam - práticas sociodiscursivas do mundo real.

As únicas atividades que envolvem produção textual/discursiva por parte dos alunos não requerem colaboração nem uso de ferramentas digitais. Em uma atividade de produção escrita - Put it in writing - os alunos devem escrever em um papel seus depoimentos sobre hábitos de aprendizagem digital, e em uma atividade oral devem entrevistar um colega. O gênero é apresentado e explorado previamente através de uma atividade de audição de uma gravação por quatro falantes. O Manual do Professor sugere em nota na página que os alunos publiquem seus depoimentos (separados por grupos) nas paredes da sala de aula. Isto pode ser visto como bastante simbólico da manutenção da produção entre as quatro paredes da sala de aula, quando poderia ser realizada ou transcrita em outro momento em uma mídia digital que permite publicação de textos para uma audiência autêntica, promovendo a agência social dos alunos. A produção é individual, em mídia impressa e a interação dos textos se restringe a mera leitura sem maior colaboração entre alunos e interação de seus textos/discursos com o mundo real em práticas sociodiscursivas autênticas com as quais eles podem estar familiarizados ao menos na língua materna.

$\mathrm{Na}$ seção Going beyond, as sugestões de leitura sobre gêneros discursivos e literários, como fan fiction, e de ferramentas digitais surgidas com o advento das possibilidades de colaboração na internet, como blogs, wikis e podcasts, são desvinculadas de tarefas, de forma que o aluno pode acessar se tiver curiosidade apenas, não tendo um motivo real pedagógico e sem que se realize uma verdadeira integração entre os gêneros digitais (seja em leitura e análise ou na produção), as ferramentas de produção de textos digitais multimodais em colaboração com o mundo real, e a sala de aula.

Em contraste, a última atividade da unidade - In their shoes - se caracteriza como uma tarefa autêntica que envolve criar e colaborar, porém a ser realizada sem utilizar uma ferramenta digital. A atividade pede que os alunos se organizem em grupos, proponham um jogo eletrônico para o mercado brasileiro e apresentem a ideias aos colegas oralmente. 


\section{Relação entre o discurso do livro do professor e as atividades em uma unidade do livro do aluno}

As atividades digitais da unidade em geral preveem uma resposta correta, portanto, na maioria dos casos não constituem práticas didáticas como meio de transformação e aprimoramento de uso da tecnologia. A atividade que mais se aproxima de tal possibilidade é apenas com relação a estimular um olhar ligeiramente crítico ao dirigir a atenção dos alunos para a fonte do texto e o meio em que é veiculado na internet.

Acredito, assim como Lemke (2012, pp 26-27), que "precisamos pensar um pouco em como as novas tecnologias da informação podem transformar nossos hábitos institucionais de ensinar e aprender". Para o autor, as novas tecnologias vão mudar o equilíbrio entre o paradigma de aprendizagem curricular e o paradigma de aprendizagem interativa, que Roxane Rojo (2012) complementa alterando o termo para aprendizagem colaborativa.

Quanto a oportunizar maior interação real em contextos autênticos de comunicação sobre assuntos atuais e relevantes e desta forma expandir as experiências de aprendizagem em atividades face-a-face em sala de aula, as atividades trazem textos autênticos, porém elas em si não poderiam ser categorizadas como tarefas exceto pela última - In their shoes, em que se propõe uma tarefa colaborativa em que os alunos são solicitados a expressar na língua suas próprias ideias conjuntas, porém sem utilizar um meio digital autêntico.

Por fim, com relação a estímulo, recomendações e incentivo à utilização de certas ferramentas para ampliar oportunidades de interações reais em contextos autênticos de comunicação, isto não é de fato preconizado nas atividades pedagógicas propostas na unidade analisada do livro do aluno, visto que não há integração entre as atividades pedagógicas e as ferramentas digitais através de tarefas autênticas. Nem sequer para facilitar e respaldar o trabalho de edição e apresentação de textos e expandir as atividades de interação oral em sala de aula há tal estímulo através de tarefas, há apenas uma orientação desvinculada das atividades pedagógicas conforme referido anteriormente. 


\section{CONSIDERAÇÕES FINAIS}

Este artigo apresenta uma análise do volume 3 do livro didático de inglês Prime que aponta para a falta de uma plena adequação entre as atividades didáticopedagógicas da unidade 2 à proposta teórico-metodológica com relação à promoção de letramento digital assumida pela coleção explicitada no Manual do Professor. O trecho sobre letramento didático indica uma representação de práticas didáticas como meio de transformação e aprimoramento de uso da tecnologia com a função de oportunizar maior interação real em contextos autênticos de comunicação sobre assuntos atuais e relevantes e desta forma expandir as experiências de aprendizagem em atividades facea-face em sala de aula. No entanto, tais objetivos são sugeridos de forma bastante modalizada, demonstrando pouco compromisso com os possíveis resultados a serem alcançados.

Conforme mencionado na introdução, o letramento digital pode servir para a oportunização de empoderamento e inserção em práticas sociodiscursivas autênticas importantes para o exercício da cidadania no e através do meio digital, porém as atividades analisadas não são propícias para realizar tal objetivo por não serem tarefas autênticas, não estimularem a interação social pelo uso da língua em meio digital nem sua simulação.

As atividades didáticas analisadas não são elaboradas de forma a fazer com que o aluno realmente seja ativo no processo de construção ativa de conhecimento. $\mathrm{O}$ aluno não tem grandes alternativas ou opção de escolhas informadas para análise nem produção de textos multisemióticos em tarefas sociodiscursivas autênticas. As relações de poder preestabelecidas não são passíveis de subversão ou transgressão através das atividades propostas na unidade sobre aprendizes digitais. Embora as outras unidades não tenham sido avaliadas, é possível supor que elas não apresentem uma revolução com relação à unidade com o tema mais propício a desenvolver projetos de letramento digital.

Não há no material pedagógico um estímulo mais eficiente que garanta oportunizações de experimentação com a língua em colaboração de forma a estimular a apropriação de gêneros digitais, menos ainda uma transformação de conhecimento coconstruído para uso no mundo real. Isto poderia ser feito através da elaboração de tarefas que tornem tais ferramentas intrínsecas ao processo pedagógico. Portanto, o 
meio digital figura na unidade de forma meramente decorativa, conceitual e passiva na aprendizagem. $\mathrm{Na}$ melhor das hipóteses as atividades contribuem para um conhecimento técnico, abstrato e normativo das linguagens digitais.

A proposta teórico-metodológica assumida pela coleção conforme explicitada no Manual do Professor com relação a letramento digital condiz em parte com uma perpectiva sociointeracionista de ensino e uma pedagogia de (multi)letramentos, porém a linha didático pedagógica das atividades propostas na unidade 2 (Are you a digital learner?) não estimula o uso de ferramentas digitais, apenas sugere. No entanto, como o Manual se propõe a uma possível transformação do conhecimento digital num discurso bastante modalizado, pode-se dizer que há relativa coerência entre o que se propõe e o que se pratica de fato nas atividades da unidade didática.

Talvez o que falte ao material seja mais assertividade e ambição de promover de fato letramento digital crítico aos moldes da teoria de (multi)letramentos e sociointeracional através do uso de tarefas autênticas que utilizem ou simulem o uso de NTICs em práticas sociodiscursivas do mundo real.

\section{REFERÊNCIAS}

BAKHTIN, M. M. [1952] Os gêneros do discurso. In: BAKHTIN, M. M. [1979] Estética da criação verbal. 4 ed. São Paulo: Martins Fontes, 2003.

BAKHTIN/VOLOCHINOV [1929] Marxismo e filosofia da linguagem. 12 ed. São Paulo: Hucitec, 2006

BRASIL. Ministério da Educação, Secretaria de Educação Básica. Guia de livros didáticos : PNLD 2015 : língua estrangeira moderna : ensino médio.Brasília : MEC/SEB 2014. Disponível em http://www.fnde.gov.br/arquivos/category/125guias?download=9006:pnld-2015-lingua-estrangeira-moderna

BRASIL. Ministério da Educação, Secretaria de Educação Básica. In: Orientações curriculares para o ensino médio. Volume 1: Linguagens, códigos e suas tecnologias. Brasília, 2006. p. 18-46; p. 87-164. Disponível em http://portal.mec.gov.br/seb/arquivos/pdf/book_volume_01_internet.pdf.

COPE, B. \& KALANTZIS, M. Eds. Multiliteracies: literacy learning and the design of social futures. London \& New York: Routledge, 2000.

COSCARELLI, C. Viana; RIBEIRO, A. (Orgs.). Letramento digital: aspectos sociais e possibilidades pedagógicas. Belo Horizonte: Autêntica, 2005.

DIAS, R.; JUCÁ, L; FARIA, R. PRIME - Inglês para o Ensino Médio. 2.ed. São Paulo: Macmillan. 2010. 
FAIRCLOUGH, N. Critical Discourse Analysis: the critical study of language. Longman, 1995/2010.

GILL, R. Análise de discurso. In: BAUER, M. W.; GASKELL, G. Pesquisa qualitativa com texto, imagem e som: um manual prático. 8. ed. Petrópolis: Vozes, 2010.

HALLIDAY, M.A.K. Halliday's introduction to Functional Grammar. Routledge, 2014.

HARWOOD, N. (Ed.) English Language Teaching Materials: Theory \& Practice. Cambridge: Cambridge University Press, 2010.

KALANTZIS, M.; COPE, B. Literacies. Cambridge: Cambridge University Press, 2012.

MARCUSCHI, L. A. Produção de texto, análise de gêneros e compreensão. São Paulo: Parábola Editorial, 2008.

PEREIRA, A.; GOTTHEIM, L. (Orgs.) Materiais didáticos para o ensino de língua estrangeira: processos de criação e contextos de uso. Campinas: Mercado de Letras, 2012.

RIBEIRO, Otacílio José. Educação e novas tecnologias: um olhar para além da técnica. In COSCARELLI, Carla Viana; RIBEIRO, Ana Elisa (Orgs). Letramento Digital: aspectos sociais e possibilidades pedagógicas. Belo Horizonte: Autêntica, 2005.

ROJO, R.; MOURA, E. (Org.). Multiletramentos na escola. São Paulo: Parábola, 2012.

TOMLINSON, B. (Ed.) Materials development in language teaching. 2 ed. Cambridge: Cambridge University Press, 2011.

VYGOTSKY, L. S. [1978]. A formação social da mente. 7 ed. São Paulo: Martins Fontes, 2007.

WIDDOWSON, $\mathrm{H}$. The authenticity of language data. In: WIDDOWSON, $\mathrm{H}$. Explorations in Applied Linguistics. Cambridge: CUP, 1979

\section{A AUTORA}

Raquel Rodrigues é mestra em Linguística Aplicada pela Universidade Federal do Rio de Janeiro. Sua área de interesse engloba (multi)letramentos, material didático, ensino de inglês, Linguística Aplicada Transgressiva e mais recentemente Linguística Queer. Atua como professora de inglês na Cultura Inglesa há mais de dez anos e colaboradora na editora Learning Factory, elaborando material didático impresso e digital há mais de cinco.

E-mail: mzrodriguez@gmail.com 